\title{
LOS CUCHILLOS DE ALBACETE
}

\author{
POR \\ JUAN J. RODRIGUEZ LORENTE
}

DE la larga y honrosa tradición española en la fabricación artesana de aceros para armas blancas, que alcanzó su cima en los siglos XVI y XVII, y desapareció casi totalmente en el xvili con la importación de los espadines franceses puestos de moda por la corte de don Felipe $V$ de Borbón, puede decirse que no queda en nuestros días vestigio alguno, si se exceptúan los modestos esfuerzos estatales centralizados en la Fábrica Nacional de Armas de Toledo, y la pujante industria cuchillera de Albacete.

La creación de Fábrica de Toledo, loable intento de recuperación de la industria, patrocinado por don Carlos III de Borbón sobre 1760, merece un estudio aparte, y desde luego no puede considerarse como una continuación de la artesanía toledana del siglo anterior, que para entonces había desaparecido totalmente, como parece evidenciar el hecho de que sólo pudo encontrarse un viejo maestro valenciano, Luis Calixto, para ocupar la dirección de la nueva Fábrica (Leguina, La espada española, 1914).

Por el contrario, la pujanza de la industria cuchillera de Albacete en el siglo xvin que puede detectarse por el considerable número de muestras de su producción que han llegado hasta nosotros, y su posterior desarrollo en el siglo XIX que enlaza con la época actual, nos hacen pensar en una larga y sostenida tradición cuchillera netamente española. A mayor abundamiento existen otros centros cuchilleros de importancia localizados también en la llanura manchega que han sobrevivido hasta hoy, entre ellos el correspondiente a la producción de hoces en La Solana.

Hace varios años, en nuestro intento de investigar esta interesante faceta de la cuchillería española, nos pusimos en contacto con el erudito investigador, ya fallecido, ilustrísimo señor don Joaquín Sánchez Jiménez, director del Museo Arqueológico de Albacete y entusiasta estudioso de la historia y arte de la región. En aquella entrevista don Joaquín nos comunicó su intención de publicar el resultado de sus investigaciones sobre el gremio de cuchilleros de Albacete, trabajo este esencial para el conocimiento de la cuchillería albaceteña, que el fallecimiento de su autor ha dejado lamentablemente inédito. Recientemente hemos tenido el gusto de saludar en Albacete a los descendientes del ilustre investigador, quienes nos han prometido repasar sus notas, siendo de celebrar que apareciesen 
aquellas relativas a la cuchillería que permitiesen su publicación a título póstumo.

En casi todas las grandes colecciones de armas, y en las armerías de museos nacionales y extranjeros, se conservan ejemplares de estos cuchillos, que en algunos casos son catalogados simplemente como «arma española», e incluso en algunos casos como «cuchillo catalán» sin duda por la procedencia del ejemplar catalogado, lo que no es de extrañar dada la abundancia con que se encuentran estas armas en el sur de Cataluña.

Entre los ejemplares que han sido publicados en el extranjero recordamos los números 26.145.175 y 26.145.171 del Metropolitan Museum de Nueva York, ambos típicamente albaceteños del siglo XvııI, y algunos ejemplares del Museo de South Kensington, en Londres, como el número 2238.55 mencionado por don Juan F. Riaño (The Industrial Arts in Spain, 1890).

En España, aparte de los ejemplares existentes en el Museo Arqueológico Nacional, y que no han sido publicados aún, salvo error por nuestra parte, existen varios cuchillos en el Instituto Valencia de Don Juan, publicados por Florit-Sánchez Cantón en el Catálogo de las Armas del Instituto, así como algún ejemplar mencionado en el Catálogo de la Real Armería.

\section{Antecedentes históricos}

El señor Rico publicó, en 1871, La cucbillería y cucbilleros de Espa$\tilde{n} a$, y posiblemente el mismo Rico Sinovas que cita Riaño como autor del artículo en el Almanaque del Museo de la Industria, 1872, dan fe de la existencia de los siguientes maestros cuchilleros que trabajaron en Albacete.

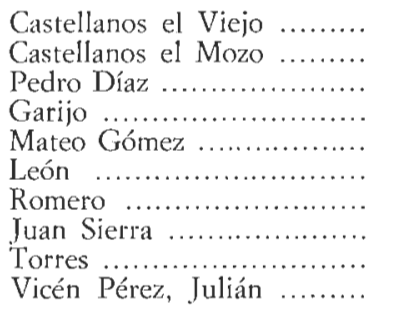

Albacete, 1766

Albacete, siglo xvili

Albacete, comienzos siglo xvIII

Albacete, 1771

Albacete, 1659

Albacete, comienzos siglo xVIII

Albacete, 1769

Albacete, 1771

Albacete, siglo xviri

Albacete, 1710

Como puede observarse, la lista comprende casi exclusivamente maestros cuchilleros del siglo XviII, por lo que la parte más interesante del posible desarrollo de la industria en su faceta artística, la de los siglos XVI 
y xvir, con la fuerte influencia árabe aún reciente en el primero, y con la expansión del segundo, permanecen en la oscuridad.

Aparte de lo anterior poco más pude encontrar que sirva para documentar la fabricación albaceteña, por lo que hemos de recurrir como fuente principal y casi única al estudio de los ejemplares que han llegado hasta nosotros.
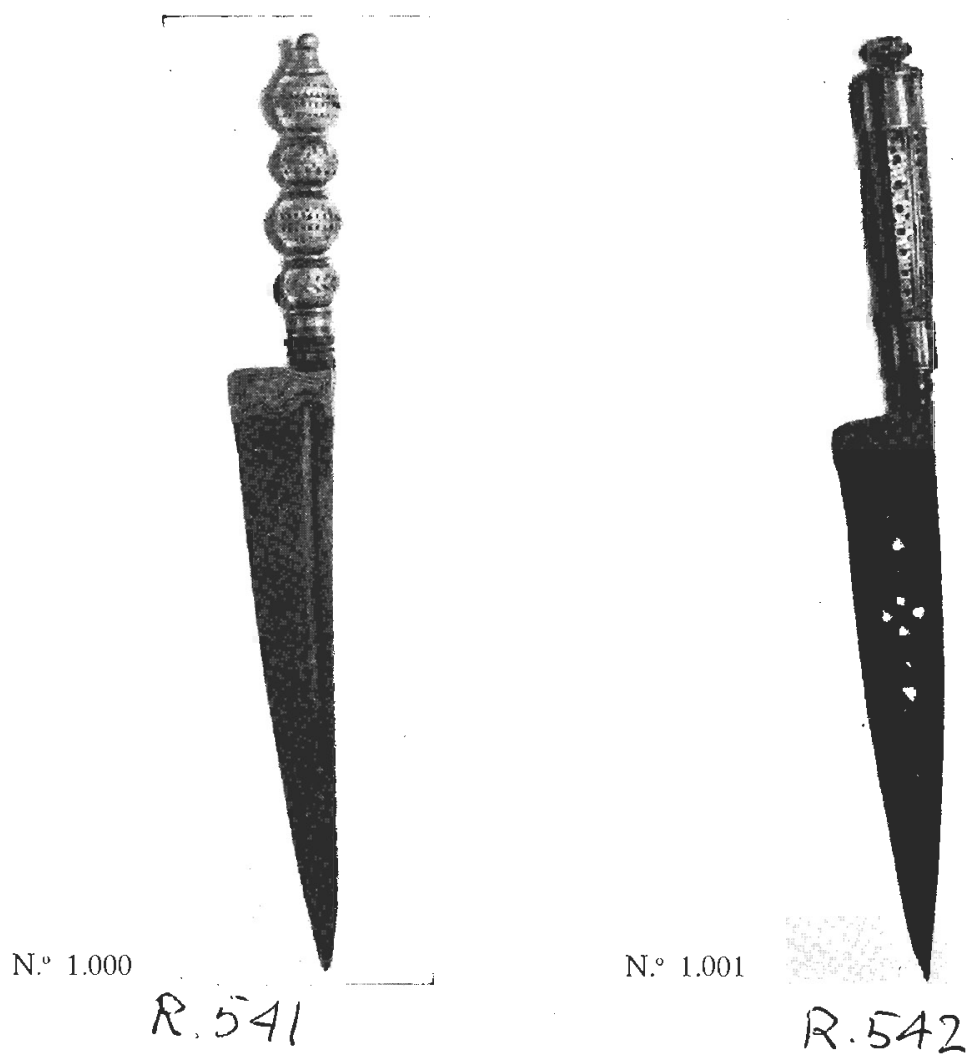

Generalidades del aspecto artístico

El mismo Riaño, en su obra antes citada, menciona un cuchillo de Albacete con la inscripción arábiga «Mataré tus enemigos con la ayuda de Dios», y en el reverso de la misma hoja «Fábrica de navajas de Antonio González. Albacete, 1705». La cita anterior confirma la primera im- 
presión que producen estos cuchillos, cuyos adornos delatan inmediatamente su origen árabe, y que en la mayoría de los modelos siguen una tradición artística que parece haberse conservado intacta aún desde tiempos anteriores a la ocupación musulmana, pues en el tipo más abundante del que se fabricaron y aún se fabrican puñales y cuchillos, la decoración del mango conserva características que nos recuerdan el arte visigodo (véanse números 1.003 y 1.005 ).
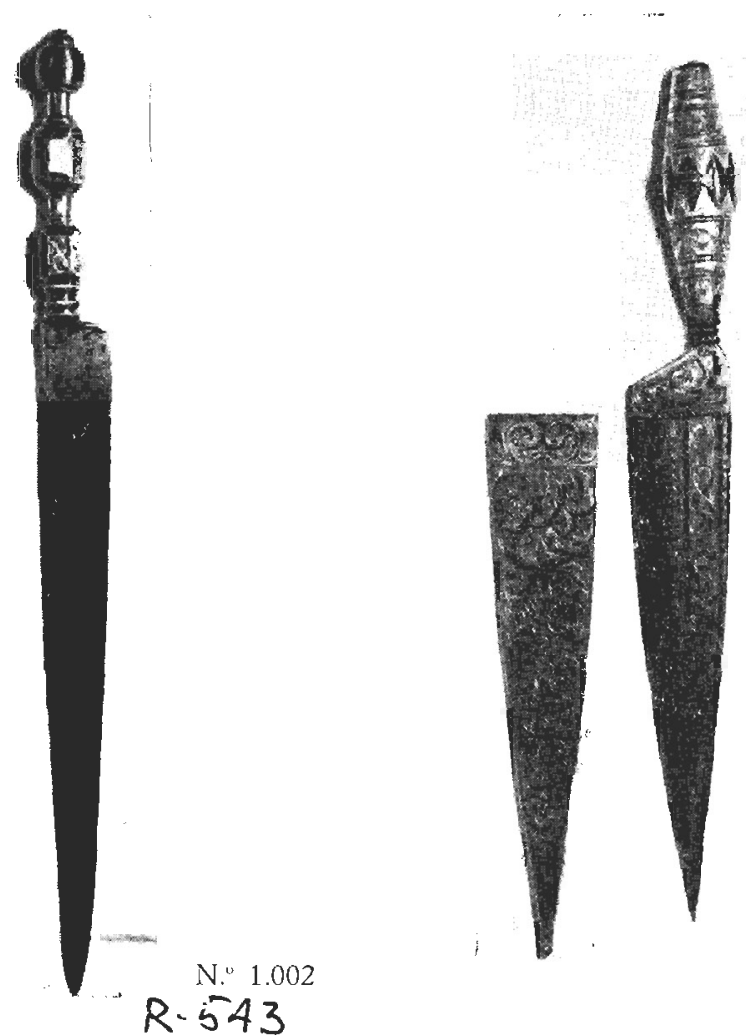

Consideramos también la cita anterior de Riaño como de gran importancia para el estudio del arte de estas pequeñas armas españolas, pues muestra la evidencia de que se hayan conservado hasta el siglo xviIr no sólo el arte del adorno, sino también algunas de las leyendas que cabe imaginar eran muy abundantes en épocas anteriores, siguiendo la mejor tradición árabe y que más tarde se convirtieron en leyendas cristianas 
frecuentes no sólo en armas, sino en otros varios utensilios domésticos españoles.

En principio, podríamos distinguir dos tipos fundamentales de las armas objeto de nuestro estudio. El primero está constituido por aquellos cuchillos y puñales cuyo mango o empuñadura está básicamente formado por las armaduras metálicas a base de platillos o arandelas unidas por nervaturas longitudinales y con sus huecos rellenados en algunos

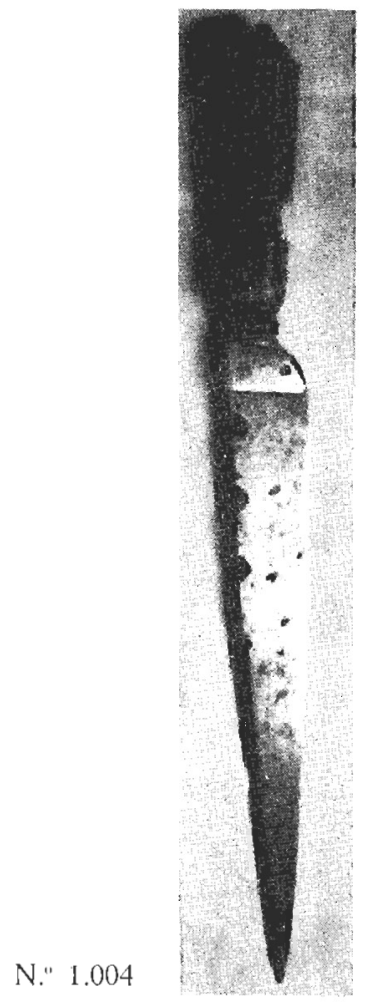

$$
\text { R.545 }
$$

N. 1.005

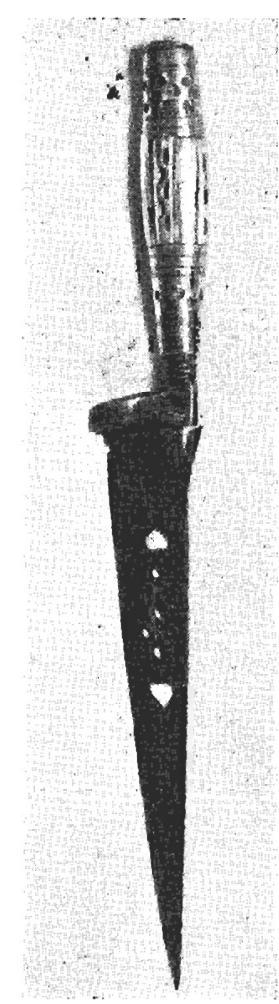

$R 546$

casos por asta o hueso. Este es el tipo de fuerte sabor árabe y aun visigodo, cuya artesanía ha sido transmitida de generación en generación hasta nuestros tiempos.

El segundo tipo lo forman los cuchillos de arzón, de mango curvado, claveteado en muchos casos, y que han sido llamados impropiamente 
«Dagas de misericordia». De estas dagas dice el señor Florit y Arizcun en su Catálogo de las Armas del Instituto de Valencia de Don Juan lo siguiente:

«Contra la creencia general, muy extendida, sobre todo en el siglo XIX, de que estas armas servían para dar el golpe de gracia al enemigo herido, opinamos que sólo eran propias de rufianes, y no hay porqué designarlas con el nombre de dagas de misericordia. Todas las que conocemos de esta forma datan de fines del siglo XVII o principios del XviII.»

Se han fabricado también este tipo de dagas en Madrid, pues hemos visto algunos ejemplares del siglo xviri con la marca de la $M$ coronada.

Del tipo primero ilustramos a continuación varios ejemplares básicos,

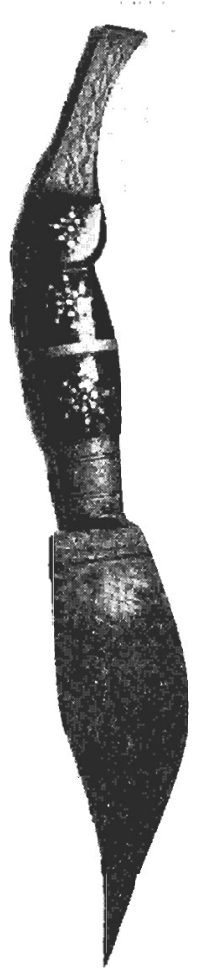

42

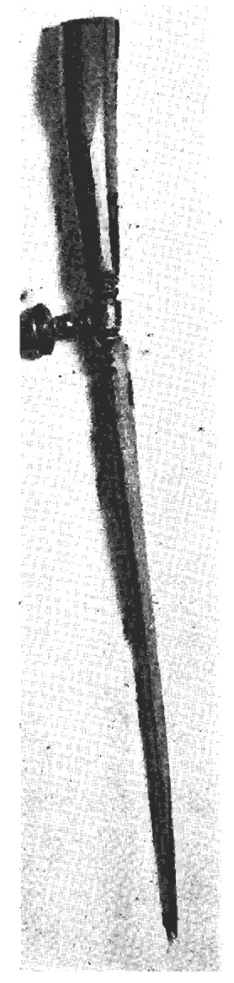

N." $1.007-\mathrm{a}$

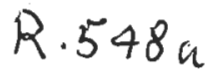

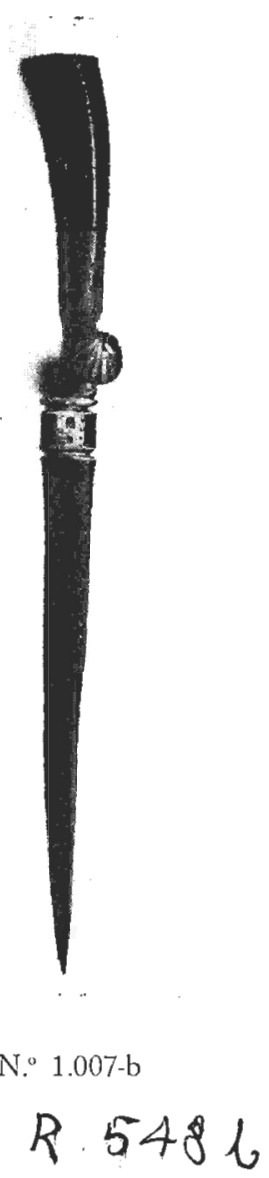


cuyos detalles pueden apreciarse en las fotografías, y que por conveniencia describimos a continuación:

\section{Númcro 1.000. CUCHILLO}

Longitud total $30,5 \mathrm{~cm}$.

Longitud de la hoja ............. $20 \mathrm{~cm}$.

Ancho máximo de la hoja ........ $3,5 \mathrm{~cm}$.

Grueso máximo de la hoja ...... $0,4 \mathrm{~cm}$.

Es uno de los ejemplares menos corrientes entre los que conocemos, por la elaborada decoración del mango. Es evidente la fuerte influencia arabizante, con esferas de latón calado, que nos recuerdan las lámparas de las mezquitas. No tiene vaina, y la punta parece haber estado rota y haber sido afilada posteriormente.

\section{Número 1.001. CUCHILLO}

Longitud total

$31,7 \mathrm{~cm}$.

Longitud de la hoja .............. $19 \mathrm{~cm}$.

Ancho máximo de la hoja ......... $3,5 \mathrm{~cm}$.

Grueso máximo de la hoja ..... $0,4 \mathrm{~cm}$.

El mango de este cuchillo con secciones de madera claveteada es, por contraste con el anterior, de factura muy corriente.

\section{Número 1.002. CUCHILLO}

Longitud total

$38,7 \mathrm{~cm}$.

Longitud de la hoja ............ $27 \mathrm{~cm}$.

Ancho máximo de la hoja ........ $2,9 \mathrm{~cm}$.

Grueso máximo de la hoja ..... $0,5 \mathrm{~cm}$.

De longitud excepcional, tiene el mango de acero cincelado y latón incrustado y la hoja grabada con motivos florales.

\section{Número 1.003. CUCHILLO}

Longitud total

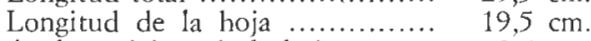

Ancho máximo de la hoja ........ $3,5 \mathrm{~cm}$.

Grueso máximo de la hoja ..... $0,3 \mathrm{~cm}$.

Mango de madera claveteada y forrada de latón con cincelado de adornos florales. Vaina de latón adornada de igual forma que el mango. 
Número 1.004. CUCHILLO

Longitud total .................. $24,5 \mathrm{~cm}$.

Longitud de la hoja ........... $16,5 \mathrm{~cm}$.

Ancho máximo de la hoja ........ $2 \mathrm{~cm}$.

Grueso máximo de la hoja ..... $0,4 \mathrm{~cm}$.

El mango formado por platillitos de latón.

Número 1.005. CUCHILLO

Longitud total ................... $27,5 \mathrm{~cm}$.

Longitud de Ia hoja ............. $16,23 \mathrm{~cm}$.

Ancho máximo de la hoja ........ $2,3 \mathrm{~cm}$.

Grueso máximo de la hoja ..... $0,3 \mathrm{~cm}$.

Hoja agujereada con adornos en forma de círculos y corazones. Mango de latón con madera al fondo y hueso. Vaina de latón con muelle.

Número 1.006. NAVAJA

Longitud total

$36,5 \mathrm{~cm}$.

Longitud de la hoja ............ $17,5 \mathrm{~cm}$.

Ancho máximo de la hoja ....... $5,1 \mathrm{~cm}$.

Grueso máximo de la hoja ..... $0,2 \mathrm{~cm}$.

Mango de latón y asta. Posiblemente fabricada como objeto ornamental, pues la hoja sujeta al mango por un solo remache parece de unión poco resistente a efectos prácticos.

Del tipo segundo ilustramos solamente el ejemplar cuyas características se detallan a continuación:

Número 1.007. CUCHILLO DE ARZON

Longitud total .................... $34 \mathrm{~cm}$.

Longitud de la hoja ............ $22 \mathrm{~cm}$.

Ancho máximo de la hoja ........ $2,1 \mathrm{~cm}$.

Grueso máximo de la hoja ..... $5,5 \mathrm{~cm}$.

Mango de asta curvada y engruesado hacia afuera. Hoja triangular alargada, de un solo filo, con recazo cincelado del que se proyecta normalmente a la hoja una espiga torneada de dos centímetros de longitud rematada por botón de dos centímetros de diámetro adornado en su cara externa por cincelado en forma de venera. El mismo adorno se repite en el platillito de acero que remata el mango y sirve de pomo. 